Document downloaded from:

http://hdl.handle.net/10251/49167

This paper must be cited as:

Fombuena, V.; Balart Gimeno, JF.; Boronat, T.; Sánchez-Nácher, L.; García-Sanoguera, D. (2013). Improving mechanical performance of thermoplastic adhesion joints by atmospheric plasma. Materials and Design. 47:49-56. doi:10.1016/j.matdes.2012.11.031.

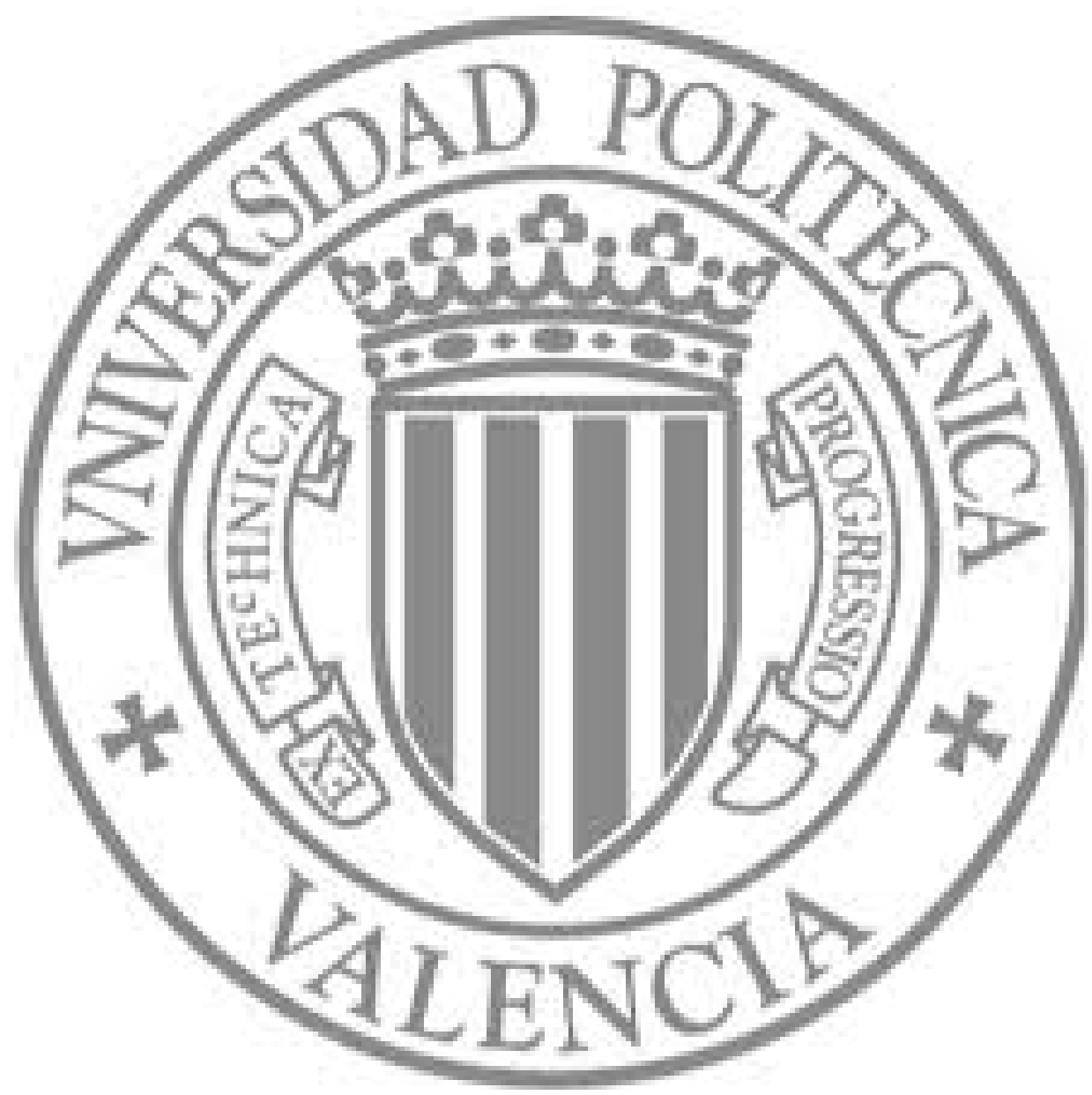

The final publication is available at

http://dx.doi.org/10.1016/j.matdes.2012.11.031

Copyright Elsevier 


\section{IMPROVING MECHANICAL PERFORMANCE OF THERMOPLASTIC ADHESION JOINTS BY ATMOSPHERIC PLASMA}

V. Fombuena, J. Balart, T. Boronat, L. Sánchez-Nácher, D. Garcia-Sanoguera Universitat Politècnica de València (UPV), Instituto de Tecnología de Materiales (ITM) Plaza Ferrándiz y Carbonell sn, 03801, Alcoy (Alicante), SPAIN

Corresponding author: D. Garcia-Sanoguera Universitat Politècnica de València

Plaza Ferrandiz y Carbonell, sn 03801 Alcoy (Alicante) SPAIN

E-mail: dagarsa@dimm.upv.es

Tel.: +34 966528429

Fax: +34 966528433 


\begin{abstract}
Polyethylene (PE) is characterized by low surface energy as a consequence of its non-polar nature. This characteristic is responsible for poor adhesion properties on polyethylene substrates. It is well known that some industrial applications such as coating, painting and formation of adhesion joints require high surface energy to promote good anchorages, so that, the use of polyethylene in these applications needs a previous surface treatment. In this work atmospheric plasma has been used to promote surface activation on polyethylene substrates for improved adhesion properties. The work has been focused on analyzing the influence of some variables (treatment rate and nozzle-sample distance) on mechanical performance of PE-PE adhesion joints subjected to shear and T-peel tests.
\end{abstract}

Keywords: atmospheric plasma; polyethylene; adhesion joint; mechanical properties; treatment conditions; surface modification 


\section{Introduction.}

Polyethylene (PE) is a widely used polymer at industrial level due to an excellent combination of easy processing, electrical insulation, chemical barrier properties, It is characterized by a relatively low surface energy due to its non-polar nature and this allows the use of polyethylene in applications in which chemical inertness is required such as medical devices, packaging industry, childcare products, etc. [1]. Nevertheless, the use of polyethylene is not only restricted to these applications. The wide availability of commercial grades together with a wide range of mechanical and thermal properties allows polyethylene to fulfill more exigent requirements for other technological sectors [2]. Many of these technical applications require higher surface energy values in order to obtain stable paints, coatings, adhesion joints with other materials, etc. [3]. As polyethylene is characterized by a marked hydrophobic behavior resulting from its non-polar nature together with very smooth surfaces, it is necessary in many cases to carry out a previous surface treatment to promote the appropriate changes (mainly chemical and surface topography changes) in order to increase surface activity thus enhancing anchorage processes typical of paints, coatings and adhesion joints [4-6].

There are a wide variety of processes to increase adhesion properties of polymer substrates. These can be sorted into chemical, physical or combined processes [7, 8]. In general terms, in chemical processes, polymer surface is exposed to different chemicals (acids, oxidants, monomers, etc.). In some cases no additional elements are needed and surface modification occurs by dipping the polymer into a chemical bath, which contains the appropriate chemical agent $[9,10]$. In other cases, additional processes are needed to activate chemicals. This is the case of surface functionalization by using monomers. Activation of monomers requires the use of different additives (thermal or 
photo-initiators) followed by exposition to selected temperature or light wavelength. In general terms, this exposition promotes some surface abrasion, deposition (which is responsible for topography changes) and surface functionalization by insertion of selected chemical groups. Combination of these two mechanisms can be responsible for remarkable changes in surface wetting properties and this can lead to an overall increase in adhesion properties [11]. The main disadvantage of these chemical processes is the use of wet processes with aggressive chemicals [12].

As an environmentally friendly solution to chemical wet processes, it is possible to selectively increase surface wettability and consequently adhesion properties by physical processes. These are characterized by exposition of the polymer surface to the action of different radiations such as ultraviolet light, $\gamma$-radiation, $\beta$-radiation, laser, non-thermal plasmas, etc. In the last years, atmospheric plasma has become an interesting alternative to chemical processes since it allows surface modification in a dry process, which leads to high environmental efficiency [13-16]. The action of the plasma gas can promote surface abrasion or etching due to removal of low molecular weight oxidized material (LMWOM) and this can produce changes in surface topography [17]. On other hand, the highly unstable species present in the plasma gas promote chain scission and subsequent free radical formation on the topmost layers of the polymer surface [18]. These highly unstable free radicals can react with oxygen, nitrogen or other gases during or after exposition to plasma to interlock certain chemical functionalities depending on the general conditions of the plasma treatment [19, 20]. Atmospheric plasma meets the advantages of both corona and low-pressure plasmas since it can be applied in a continuous way (such as corona) but the plasma gas is not only restricted to air, so that different gases such as $\mathrm{O}_{2}, \mathrm{CO}_{2}, \mathrm{~N}_{2}$, Ar, etc. can be used (in a similar way to a low-pressure plasma) [12, 13]. Even, plasmapolymerization can be 
conducted on atmospheric plasma reactors if the appropriate plasma mixture gas or monomer is used [21], in addition plasma processed combined with UV photografting can show a good results regarding to adhesion properties [22]. The absolute control of all parameters in atmospheric plasma leads to good homogeneity on treated-surfaces and this, together with the easy online implementation with other industrial operations, makes atmospheric plasma an attractive alternative to wet-batch chemical processes [19, 23].

The main aim of this work is to use atmospheric plasma with dry air to increase surface wettability of polyethylene substrates in order to improve mechanical performance of polyethylene-polyethylene adhesion joints. The work is focused on the quantification of the surface changes (chemical and topographical) of polyethylene subjected to atmospheric plasma treatment. The effect of different variables (nozzlesample distance and treatment rate) on overall performance of PE-PE adhesion joints with conventional polyurethane adhesive type has also been studied. The mechanical response of PE-PE adhesion joints has been tested in shear and T-peel modes and scanning electron microscopy has been used for characterization of fractured adhesion joints.

\section{Experimental details.}

\subsection{Materials.}

The base polymer for surface modification was a low density polyethylene (LDPE) commercial grade ALCUDIA PE.019 supplied by Repsol YPF (Repsol YPF, Madrid, Spain) with a melt flow index, MFI= $20 \mathrm{~g} / 10 \mathrm{~min}$ and a density of $\rho=919$ $\mathrm{kg} / \mathrm{m}^{3}$. This grade is suitable for injection molding with a recommended injection

temperature of $190{ }^{\circ} \mathrm{C}$. Sheets sizing $160 \times 60 \times 2 \mathrm{~mm}^{3}$ were obtained with convention 
injection molding with a Mateu-Solé, mod. 270/5 (Mateu-Solé S.A., Barcelona, Spain). After this, samples sizing $10 \times 10 \times 2 \mathrm{~mm}^{3}$ were cut in order to guarantee homogeneous treatment with the plasma nozzle.

\subsection{Atmospheric plasma treatment.}

Polyethylene samples were subjected to atmospheric plasma with a plasma generator FG 3001 supplied by Plasmatreat (Plasmatreat GmbH, Steinhagen, Germany). This generator operates at 50/60 Hz, $230 \mathrm{~V}$ and $16 \mathrm{~A}$, with a frequency of $17 \mathrm{kHz}$ and a discharge voltage of $20 \mathrm{kV}$. The plasma treatment was applied using a rotating torch ending in a nozzle with a rotation speed of $1900 \mathrm{rpm}$. To evaluate the influence of the nozzle-sample distance, different distances in the $6-20 \mathrm{~mm}$ range were selected. On other hand, the treatment rate was set in the $100-1000 \mathrm{~mm} \mathrm{~s}^{-1}$ range.

\subsection{Contact angle measurements and surface energy calculation.}

Changes in wetting properties of polyethylene substrates were followed by contact angle measurements using EasyDrop Standard goniometer, model FM140 supplied by KRÜSS (KRÜSS GmbH, Hamburg, Deutchland) with a measurement range from 1 to $180^{\circ} \mathrm{C}$ with a precision of $\pm 0.1^{\circ} \mathrm{C}$. This equipment is supplied with a video capture kit and analysis software (Drop Shape Analysis SW21; DSA1). To obtain stable values, contact angle measurements were carried out five minutes after the plasma treatment. The maximum error in the contact angle measurement did not exceed $\pm 3 \%$. Different test liquids were used for contact angle measurements: diiodomethane stabilized, >99\% purity, supplied by Acros Organics (Acros Organics, Geel, Belgium), formamide reagent grade ACS, supplied by Scharlau Chemie S.A. (Scharlab S.L., Barcelona, Spain), glycerol $>99 \%$ purity supplied by Scharlau Chemie S.A. (Scharlab 
S.L., Barcelona, Spain) and double distilled water. Contact values for the four test liquids used for contact angle measurements can be observed in Table 1.

\section{Table 1}

Surface free energy values were calculated using the Owens-Wendt method which takes into account the dispersive (non polar) and polar contribution to the total surface free energy value [24]. This method requires, at least, two different test liquids. As it has described before, four different test liquids have selected with different polar and dispersive behavior [25, 26].

\subsection{Surface characterization.}

X-ray photoelectron spectroscopy (XPS) was used to determine chemical changes as a consequence of the plasma treatment. The oxidation level of plasmatreated surfaces was estimated as the O/C ratio. This analysis was carried with a VGMicrotech Multilab electron spectrometer (VG Microtech Ltd, Uckfield, UK) using the $\mathrm{Mg} \mathrm{K \alpha}$ radiation (1253.6 eV) from a twin anode working in constant energy mode at a pass energy of $50 \mathrm{eV}$. The pressure of the measuring chamber was maintained at $5 \cdot 10^{-10}$ mbar. The regulation of the scale of binding energies (BE) was performed according to the C (1s) transition at $284.6 \mathrm{eV}$. The accuracy of BE values was $\pm 0.2 \mathrm{eV}$. Binding energy values were obtained using the Peak-fit program installed in the XPS spectrometer control software.

Surface topography changes were studied with atomic force microscopy (AFM) using a Multimode AFM microscope with a Nanoscope IIIa ADCS controller (Veeco Metrology Group, Cambridge, UK). A monolithic silicon cantilever Nano World Point- 
robe $^{\circledR}(\mathrm{NCH})$ with a force constant of $42 \mathrm{~N} \mathrm{~m}^{-1}$ and a resonance frequency of $320 \mathrm{~Hz}$ was used to work on the tapping mode. The samples analyzed were $20 \mu \mathrm{m}$ x $20 \mu \mathrm{m}$ in size. The maximum and minimum roughness obtained was $123.64 \mathrm{~nm}$ and $24.92 \mathrm{~nm}$ respectively.

\subsection{Characterization of adhesion joints.}

Adhesive joints were between two polyethylene substrates were prepared using a polyurethane type adhesive commercial grade 801 supplied by Adhesivos Kefren (Adhesivos Kefren S.A., Alicante, Sapin). It is a high density monocomponent polyurethane type derived from 4,4'-diphenyl diisocyanate. The amount of adhesive dosed on polyethylene substrates was $0.05 \mathrm{~g} \mathrm{~cm}^{-2}$ and after this, adhesive joints were subjected to constant pressure to avoid displacements. After 24 hours, adhesion joints were ready for mechanical characterization.

Two types of mechanical tests (shear and T-peel) were performed with a universal test machine Elib 30 (S.A.E. Ibertest, Madrid, Spain).

Shear tests were carried out following the guidelines of the ISO 13445 standard [27]; square samples sizing $25 \times 25 \times 2 \mathrm{~mm}^{3}$ were prepared and subjected to surface modification by atmospheric plasma with different rates and nozzle-sample’s distance. After this, PE-PE adhesion joints were prepared along a total length of 10-12 mm. The selected crosshead speed for the test was $50 \mathrm{~mm} \mathrm{~min}^{-1}$. At least six samples for each (treatment rate, nozzle-sample distance) combination were tested and average values of maximum shear strength were calculated.

On other hand, T-peel tests $\left(180^{\circ}\right)$ were carried out following EN 1895 standard [28]. Rectangular samples $200 \times 25 \times 2 \mathrm{~mm}^{3}$ in size were prepared and subjected to plasma treatment as described above. Once samples were treated the polyurethane 
adhesive was applied to a total length of $125 \mathrm{~mm}$. Tests were carried out at a fixed crosshead speed of $300 \mathrm{~mm} \mathrm{~min}^{-1}$. At least six samples for each (rate, nozzle-sample distance) combination were tested and average values of maximum T-peel strength values were calculated.

Characterization of fractured surfaces from T-peel and shear tests was carried with a scanning electron microscope FEI model Phenom (FEI, Oregon, USA). Prior to sample observation, samples were covered with a gold-palladium alloy in a Sputter Coater EMITECH mod. SC7620 (Quorum Technologies Ltd, East Sussex, UK).

\section{Results and discussion.}

\subsection{Characterization of wetting changes.}

As it has been stated previously, surface changes produced by the plasma treatment can modify wetting properties of polyethylene surface. To quantify surface wetting properties, contact angle measurements with different test liquids were carried. The varying parameters were nozzle-sample distance (6, 10, 14 and $20 \mathrm{~mm}$ ) and treatment rate (from 100 to $1000 \mathrm{~mm} \mathrm{~s}^{-1}$ ). Figure 1 shows a plot evolution of the contact angle variation in terms of the treatment rate for different nozzle-sample distances.

\section{Figure 1}

As it can be observed, an increasing tendency has been detected with the treatment rate increase for all the nozzle-sample distances. Maximum contact angle values are obtained for the combination involving high treatment rates and high nozzlesample distance (Figure 1d) in the selected range. Untreated polyethylene is characterized by a water contact angle of $100.1^{\circ}$. When the minimum nozzle-sample 
distance is selected, the water contact values are reduced up to values of about $20.7^{\circ}$ (which represents a percentage reduction of 79.4\%), $21.5^{\circ}$ (\% reduction $=78.51 \%$ ), $54.8^{\circ}(\%$ reduction $=45.2 \%)$ and $75.6^{\circ}(24.4 \%)$ for $100,300,700$ and $1000 \mathrm{~mm}^{-1}$ treatment rates respectively, so that, the increasing tendency with treatment rate is clearly evident. So that, short nozzle-sample distances in combination with low treatment rates are interesting to achieve good wetting properties on polyethylene substrates. Similar tendency can be observed with the other test liquids used for contact angle measurements. In the case of formamide as test liquid, the initial contact angle value for the untreated polyethylene is located at $81.0^{\circ}$. For a constant treatment rate of $100 \mathrm{~mm} \mathrm{~s}^{-1}$, the contact angle evolution shows an increasing tendency with the nozzlesample distance. In particular, it is possible to obtain a \% decrease in contact angle values ranging from $86.0 \%$ for a nozzle-sample distance of $6 \mathrm{~mm}$ up to $24.1 \%$ for a nozzle-sample distance of $20 \mathrm{~mm}$. Intermediate \% decrease in contact angles are 73.3\% and $68.2 \%$ for nozzle-sample distances of 10 and mm respectively and this confirms the increasing tendency in contact angle values with increasing nozzle-sample distance. As it has been described previously, the use of at least two different test liquids, allows calculating surface free energy (SFE) values by the Owens-Wend method. Figure 2 shows the evolution of the total surface free energy in terms of the treatment rate for different nozzle-sample distances. In this graphic, the horizontal line located at $27.4 \mathrm{~mJ}$ $\mathrm{m}^{-2}$ represents the surface free energy of the untreated polyethylene.

\section{Figure 2}

It can be clearly observed that surface free energy decreases as the treatment rate increases . High treatment rates don’t ensure enough exposition to plasma and low 
wetting properties are obtained. On other hand, the surface free energy values decrease with increasing nozzle-sample distance since short distances favor interaction between plasma gas and polymer surface. Maximum surface free energy for polyethylene is obtained for a nozzle-sample distance of $6 \mathrm{~mm}$ and a treatment rate of $100 \mathrm{~mm} \mathrm{~s}^{-1}$, with values of $62.9 \mathrm{~mJ} \mathrm{~m}^{-2}$ which represents a percentage increase of almost 229.2\% with regard to the untreated material.

\subsection{Surface morphology characterization.}

It is possible to evaluate surface topographic changes produced by the plasma treatment by using atomic force microscopy (AFM). The highly unstable species in the plasma gas collide with some polymer chains in the topmost layers. These collisions promote chain scission and subsequent free radical formation. Chain scission can lead to formation of low molecular weight oligomers, low molecular weight oxidized materials (LMWOM), which can be removed from surface thus promoting changes in surface topography. This material removal process is responsible for an etching effect, which can be observed with AFM, since changes in surface roughness can be produced. The RMS roughness can be measured in order to check the surface changes related to the etching effect [29]. Figure 3 shows surface topography of polyethylene samples subjected to atmospheric plasma with different (treatment rate, nozzle-sample distance) combinations.

\section{Figure 3}

As it can be observed, surface topography changes with treatment rate and nozzle-sample distances. The overall surface topography changes can be studied by 
following the evolution of the surface roughness ( $\mathrm{R}_{\mathrm{rms}}$ - root mean square roughness). For a fixed nozzle-sample distance of $6 \mathrm{~mm}$ and a treatment rate of 100 the $\mathrm{R}_{\mathrm{rms}}$ values is about $123.6 \mathrm{~nm}$ which represents a percentage increase of $464.6 \%$ if compared to the $R_{r m s}$ value of the untreated polyethylene surface which is $26.6 \mathrm{~nm}$. For the same nozzlesample distance $(6 \mathrm{~mm})$ and maximum treatment rate, the $\mathrm{R}_{\mathrm{rms}}$ is about $59.7 \mathrm{~nm}$. This fact indicates that abrasion/etching occurs in a less extent as the treatment rate increases because exposition of polymer surface to the action of plasma gas is restricted. When using a nozzle-sample distance of $20 \mathrm{~mm}$ and treatment rates of 100 and $1000 \mathrm{~mm} \mathrm{~s}^{-1}$, the $\mathrm{R}_{\mathrm{rms}}$ values are closed to 62.5 and $24.9 \mathrm{~nm}$ respectively which is in accordance with previous results in which a decrease in wetting properties is detected for high nozzlesample distances and increasing treatment rates.

On other hand, it is possible to obtain an overall parameter representative for surface functionalization by insertion of polar groups during the plasma treatment and subsequent exposure to air. This parameter is related to the chemical changes produced by the plasma treatment on the topmost layer of polymer surface. As the plasma gas is air and after the plasma treatment samples are exposed to air, a useful parameter representative for surface functionalization is the surface oxidation ratio defined as the $\mathrm{O} / \mathrm{C}$ ratio [30]. This can be obtained by determining the atomic composition of the polymer surface subjected to different plasma conditions (treatment rate and nozzlesample distance) using XPS. Figure 4 shows a plot representation of the evolution of $\mathrm{O} / \mathrm{C}$ ratio in terms of the nozzle-sample distance for different treatment rates.

Figure 4 
Figure 4 shows that the $\mathrm{O} / \mathrm{C}$ ratio tends to decrease for nozzle-sample distances higher than $10 \mathrm{~mm}$ for all the treatment rates considered and this indicates that functionalization by insertion of polar groups (mainly oxygen-based species due to the nature of the plasma gas and subsequent exposure to oxidizing atmosphere) occurs in a less extent for higher nozzle-sample distance since the plasma gas don't interact appropriately with the polymer surface due to the loss of efficiency of plasma treatment at these distances [31]. With regard to a nozzle-sample distance of $6 \mathrm{~mm}$, as the $\mathrm{O} / \mathrm{C}$ ratio is relatively low, this fact indicates that the surface abrasion is the main plasma acting mechanism due to aggressive action of the plasma gas which produces high material removal. In Figure 4b, it can be clearly observed a decreasing tendency on O/C ratios as the treatment rate increases; this tendency is evident for nozzle-sample distances of 10, 14 and $20 \mathrm{~mm}$ and these results are in total agreement with changes in wetting properties as described before since an increase in the treatment rate diminishes the exposure time to plasma action.

\subsection{Characterization of adhesion joints.}

To evaluate the effectiveness of the plasma treatment for adhesion purposes, plasma-treated polyethylene sheets have been joined by using a polyurethane adhesive and finally, mechanical performance of the adhesion joints has been tested in shear and T-peel modes.

Figure 5 shows a plot evolution of the shear strength as a function of the treatment rate for different nozzle-sample distances.

\section{Figure 5}


The obtained results are in total agreement with the results abovementioned. An increasing treatment rate has negative effects on mechanical performance of adhesion joints since high treatment rates do not allow enough interaction between polyethylene surface and plasma gas. It can be observed a decreasing tendency on shear stress values for all nozzle-sample distances. On other hand, increasing nozzle-sample distance has also a negative effect on shear strength as the typical plot evolution for a fixed nozzlesample distance is moved to lower shear strength values. The initial shear strength for untreated polyethylene adhesion joints is close to 0. For a fixed nozzle-sample distance of $6 \mathrm{~mm}$ and a treatment rate of $100 \mathrm{~mm} \mathrm{~s}^{-1}$ (the most aggressive conditions in the selected range for this study) leads to shear strength values of $0.9 \mathrm{MPa}$. In the opposite case (nozzle-sample distance of $20 \mathrm{~mm}$ and a treatment rate of $1000 \mathrm{~mm} \mathrm{~s}^{-1}$ ) the lowest shear strength values are obtained $(0.31 \mathrm{MPa})$ but even in this case, shear strength is higher than the values obtained with untreated polyethylene; so that, even in these conditions, the effectiveness of the plasma treatment is interesting.

Figure 6 shows different SEM images obtained from fractured samples from shear tests. Cohesive failure is observed for samples treated with plasma while an adhesive failure is dominant for the non-treated samples [32].

\section{Figure 6}

Figure 6a, obtained for a fixed nozzle-sample distance of $6 \mathrm{~mm}$ and a treatment rate of $100 \mathrm{~mm} \mathrm{~s}-1$ (aggressive conditions) shows a highly rough polyurethane surface which is representative for good adhesion to polyethylene substrates and fracture occurs within the adhesive bulk material. This is a typical mainly cohesive fracture type, which is typical of fractures performed by aggressive plasma conditions (short nozzle-sample 
distance and low treatment rate). On other hand, when less aggressive plasma conditions are used (higher nozzle-sample distance and increasing treatment rates) it can be observed smooth surface on fractured adhesion joints. This indicates that polyurethane has been almost removed from polyethylene substrates and this is representative for poor adhesion between the adhesive and the polymer substrate. This is a typical mainly adhesive fracture type and it occurs because the overall functionalization of polyethylene substrate does not occur in a great extent as increasing nozzle-sample distances and treatment rates lead to low interaction between the plasma gas and polyethylene substrate. This situation is shown in Figure 6b, which corresponds to fractured PE-PE adhesion joints in shear mode. It can be observed a quite smooth surface (if compared with more aggressive conditions shown in Figure 6a) but also some irregularities are detected. These are related to polyurethane adhesive since the fracture type is predominantly adhesive.

In a similar way, mechanical performance of PE-PE subjected to different atmospheric plasma conditions have determined in T-peel mode. Figure 7 shows the plot evolution of the T-peel strength in terms of the treatment rate for different nozzlesample distances.

\section{Figure 7}

As nozzle-samples distance increases from $6 \mathrm{~mm}$ to $20 \mathrm{~mm}$, a clear decreasing tendency on T-peel strength values (individual plots for fixed nozzle-sample distance are displaced down to lower T-peel strength values) is detected, which is in total accordance with changes in wetting properties on polyethylene substrate. On other hand, the treatment rate has also a negative effect on mechanical performance of PE-PE 
adhesion joints and a decreasing tendency is clearly evident from observation of Figure 7.

Again, the minimum T-peel strength $\left(13.8 \mathrm{~N} \mathrm{~cm}^{-1}\right)$ is obtained for adhesion joints with less aggressive conditions (nozzle-sample distance of $20 \mathrm{~mm}$ and treatment rate of $1000 \mathrm{~mm} \mathrm{~s}^{-1}$ ) and maximum values of about $50.2 \mathrm{~N} \mathrm{~cm}^{-1}$ are detected for the most aggressive conditions in the selected range (nozzle-sample distance of $6 \mathrm{~mm}$ and treatment rate of $100 \mathrm{~mm} \mathrm{~s}^{-1}$ ).

Figure 8 shows SEM images for fractured adhesion joints from T-peel tests, which can give an idea of the effectiveness of the plasma treatment for adhesion purposes.

\section{Figure 8}

The use of aggressive conditions (nozzle-distance $=6 \mathrm{~mm}$ and treatment rate $=100$ $\mathrm{mm} \mathrm{s}^{-1}$ ) leads to a rough fractured surface and the fracture type is mainly cohesive as observed in Figure 8a. Fracture occurs inside the bulk adhesive so that, it offers good adhesion between the polymer substrate and the polyurethane adhesive. As it has been described before, the effects of the plasma treatment for these conditions promotes both surface functionalization by insertion of polar groups and changes in surface topography being these two important parameters for adhesion purposes. On other hand, the use of less aggressive conditions for the plasma treatment (nozzle-sample distance $=20 \mathrm{~mm}$ and treatment rate $=1000 \mathrm{~mm} \mathrm{~s}^{-1}$ ) leads to a smooth surface which is representative for a predominantly adhesive fracture type and this is in total accordance with the previous results regarding wetting properties. This situation can be observed in Figure $8 \mathrm{~b}$ which shows a highly smooth surface with some irregularities since the plasma treatment 
promotes some surface changes even for these less aggressive conditions and this is enough to promote some interactions between the adhesive and the plasma-treated polyethylene surface. So that, these irregularities can be related to polyurethane adhesive adhered to PE substrate.

\section{Conclusions.}

Atmospheric plasma treatment with dry and pressurized air as plasma gas is an effective process to promote a remarkable increase in surface wetting properties of polyethylene which is characterized by high inertness. The increase in surface wettability is related to two main plasma-acting mechanisms: on the one hand, the action of the plasma gas promote chain scission on the topmost layers of the polyethylene substrate and this form free radicals which act as interlock points for polar groups. XPS results show that functionalization occurs by insertion of oxygen-based species since the plasma gas is oxidizing (air) and subsequent exposition to air promotes reactions with oxygen so that the overall results lead to highly oxidized surfaces (high $\mathrm{O} / \mathrm{C}$ ) ratios. On the other hand, the plasma action promotes material abrasion/removal of low molecular weight oxidized materials (LMWOM), which produces changes in surface topography. AFM study has revealed a marked increase in surface roughness as the nozzle-sample distance and the treatment rate decrease. These two plasma-acting mechanisms occur simultaneously but depending on the nozzle-sample distance and treatment rate, one can be predominant. The main plasma-acting mechanism for aggressive conditions (short nozzle-sample distance and low treatment rate) is abrasion while surface functionalization increases for less aggressive conditions.

The increase in wetting properties and surface free energy achieved by the atmospheric plasma treatment produces a remarkable increase in adhesion properties of 
polyethylene substrates. Mechanical performance of PE-PE adhesion joints with a polyurethane adhesive is considerably increased for both shear and T-peel modes. Once again, some differences are detected when using different plasma conditions. So that, the use of highly aggressive conditions leads to a mainly cohesive fracture type (for both shear and T-peel modes) and this represents good interaction between the polyurethane adhesive and the plasma treated polyethylene surface. On other hand, less aggressive conditions characterized by higher nozzle-sample distance and high treatment rates lead to a mainly adhesive fracture type due to the low wetting properties achieved with the plasma treatment in these conditions.

In conclusion, atmospheric plasma with pressurize dry air is a useful technique to provide good adhesion properties to polyethylene. In addition to this, atmospheric plasma is characterized by its high environmental efficiency and easy implementation at industrial level. 


\section{Acknowledgements}

This work is a part of the project IPT-310000-2010-037,"ECOTEXCOMP: Research and development of textile structures useful as reinforcement of composite materials with marked ecological character." funded by the "Ministerio de Ciencia e Innovacion", with an aid of 189540.20 euros, within the "Plan Nacional de Investigación Científica, Desarrollo e Innovación Tecnológica 2008-2011” and funded by the European Union through FEDER funds, Technology Fund 2007-2013, Operational Programme on $\mathrm{R}+\mathrm{D}+\mathrm{i}$ for and on behalf of the companies. Also, microscopy services at UPV are acknowledged for SEM and AFM support. 


\section{References}

[1] Sanchis RM, Calvo O, Sanchez L, Garcia D and Balart R. Enhancement of Wettability in low density polyethylene films using low pressure glow discharge N-2 plasma. J Polym Sci Pt B-Polym Phys 2007; 45:2390-9

[2] Pascual M, Calvo O, Sanchez-Nacher L, Bonet MA, Garcia-Sanoguera D and Balart R. Optimization of Adhesive Joints of Low Density Polyethylene (LDPE) Composite Laminates with Polyolefin Foam Using Corona Discharge Plasma. J Appl Polym Sci 2009; 114:2971-7

[3] De Geyter N, Morent R and Leys C. Surface characterization of plasmamodified polyethylene by contact angle experiments and ATR-FTIR spectroscopy. Surf Interface Anal 2008; 40:608-11

[4] Novak I, Steviar M, Chodak I, Krupa I, Nedelcev T, Spirkova M, Chehimi MM, Mosnacek J and Klienova A. Study of adhesion and surface properties of lowdensity poly(ethylene) pre-treated by cold discharge plasma. Polym Adv Technol 2007; 18:97-105

[5] Thurston RM, Clay JD and Schulte MD. Effect of atmospheric plasma treatment on polymer surface energy and adhesion. J Plast Film Sheeting 2007; 23:63-78

[6] Zhu L, Teng WH, Xu HL, Liu Y, Jiang QR, Wang CX and Qiu YP. Effect of absorbed moisture on the atmospheric plasma etching of polyamide fibers. Surf Coat Technol 2008; 202:1966-74

[7] Borcia C, Borcia G and Dumitrascu N. Plasma induced surface modification in relation to polymer characteristics. J Optoelectron Adv Mater 2008; 10:675-9

[8] Chen X, Yao L, Xue J, Zhao D, Lan Y, Qian X, Wang CX and Qiu Y. Plasma penetration depth and mechanical properties of atmospheric plasma-treated 3D aramid woven composites. Appl Surf Sci 2008; 255:2864-8

[9] Krump H, Hudec I, Jasso M, Dayss E and Luyt AS. Physical-morphological and chemical changes leading to an increase in adhesion between plasma treated polyester fibres and a rubber matrix. Appl Surf Sci 2006; 252:4264-78

[10] Leroux F, Campagne C, Perwuelz A and Gengembre L. Polypropylene film chemical and physical modifications by dielectric barrier discharge plasma treatment at atmospheric pressure. J Colloid Interface Sci 2008; 328:412-20

[11] Borcia C, Borcia G and Dumitrascu N. Relating plasma surface modification to polymer characteristics. Appl Phys A-Mater Sci Process 2008; 90:507-15 
[12] Fang Z, Qiu YC, Wang H and Kuffel E. Improving Hydrophobicity of glass surface using dielectric barrier discharge treatment in atmospheric air. Plasma Sci Technol 2007; 9:582-6

[13] Kusano Y, Mortensen H, Stenum B, Goutianos S, Mitra S, Ghanbari-Siahkali A, Kingshott $\mathrm{P}$, Sorensen $\mathrm{BF}$ and Bindslev H. Atmospheric pressure plasma treatment of glassy carbon for adhesion improvement. Int J Adhes Adhes 2007; 27:402-8

[14] Leroux F, Perwuelz A, Campagne C and Behary N. Atmospheric air-plasma treatments of polyester textile structures. J Adhes Sci Technol 2006; 20:939-57

[15] Moravej M and Hicks RF. Atmospheric plasma deposition of coatings using a capacitive discharge source. Chem Vapor Depos 2005; 11:469-76

[16] Villermet A, Cocolios P, Rames-Langlade G, Coeuret F, Gelot JL, Prinz E and Forster F. ALDYNE (TM): surface treatment by atmospheric plasma for plastic films converting industry. 2002; 899-901

[17] Guimond S and Wertheimer MR. Surface degradation and hydrophobic recovery of polyolefins treated by air corona and nitrogen atmospheric pressure glow discharge. J Appl Polym Sci 2004; 94:1291-303

[18] Gunther S, Teuscher N, Heilmann A, Hansel R, Voigt HM and Kiesow A. InLine Investigations of Atmospheric Pressure Plasma Processes in Correlation with Surface Analysis. J Adhes Sci Technol 2011; 25:857-68

[19] Wafa DM, Breidt F, Gawish SM, Matthews SR, Donohue KV, Roe RM and Bourham MA. Atmospheric plasma-aided biocidal finishes for nonwoven polypropylene fabrics. II. Functionality of synthesized fabrics. J Appl Polym Sci 2007; 103:1911-7

[20] Han MH, Jegal JP, Park KW, Choi JH, Baik HK, Noh JH, Song KM and Lim YS. Surface modification for adhesion enhancement of PET-laminated steel using atmospheric pressure plasma. Surf Coat Technol 2007; 201:4948-52

[21] Low SP, Short RD and Steele DA. Plasma Polymer Surfaces for Cell Expansion and Delivery. J Adhes Sci Technol 2010; 24:2215-36

[22] Balart J, Fombuena V, Espana JM, Sanchez-Nacher L and Balart R. Improvement of adhesion properties of polypropylene substrates by methyl methacrylate UV photografting surface treatment. Mater Des 2012; 33:1-10

[23] Gawish SM, Matthews SR, Wafa DM, Breidt F and Bourham MA. Atmospheric plasma-aided biocidal finishes for nonwoven polypropylene fabrics. I. Synthesis and characterization. J Appl Polym Sci 2007; 103:1900-10 
[24] Fowkes FM. Work of Adhesion - Calculation and Measurement. Ind Eng Chem 1968; 60:8-16

[25] Fowkes FM. Calculation of Work of Adhesion by Pair Potential Summation. J Colloid Interface Sci 1968; 28:493-9

[26] Owens DK and Wendt RC. Estimation of Surface Free Energy of Polymers. J Appl Polym Sci 1969; 13:1741-7

[27] ISO 13445:2003. Adhesives - Determination of shear strength of adhesive bonds between rigid substrates by the block-shear method; 2003.

[28] EN 1895:2002. Adhesives for paper and board, packaging and disposable sanitary products - $180^{\circ}$ "T" peel test for a flesible-to-flexible assembly; 2002.

[29] Fricke K, Steffen H, von Woedtke T, Schroder K and Weltmann KD. High Rate Etching of Polymers by Means of an Atmospheric Pressure Plasma Jet. Plasma Process Polym 2011; 8:51-8

[30] Abenojar J, Colera I, Martinez MA and Velasco F. Study by XPS of an Atmospheric Plasma-Torch Treated Glass: Influence on Adhesion. J Adhes Sci Technol 2010; 24:1841-54

[31] Lommatzsch U, Pasedag D, Baalmann A, Ellinghorst G and Wagner HE. Atmospheric Pressure Plasma Jet Treatment of Polyethylene Surfaces for Adhesion Improvement. Plasma Process Polym 2007; 4:S1041-S5

[32] Noeske M, Degenhardt J, Strudthoff S and Lommatzsch U. Plasma jet treatment of five polymers at atmospheric pressure: surface modifications and the relevance for adhesion. Int J Adhes Adhes 2004; 24:171-7 


\section{Figure captions}

Figure 1. Variation of contact angles in terms of the treatment rate for different nozzlesample distances: a) $6 \mathrm{~mm}$; b) $10 \mathrm{~mm}$; c) $14 \mathrm{~mm}$ and d) $20 \mathrm{~mm}$.

Figure 2. Variation of the total surface free energy $\left(\gamma_{\mathrm{s}}\right)$ of polyethylene surface in terms of the treatment rate for different nozzle-sample distances.

Figure 3. AFM 3D topographic images of polyethylene surface subjected to atmospheric plasma treatment with different combinations (nozzle-sample distance/treatment rate). a) $6 \mathrm{~mm} \mathrm{-} 100 \mathrm{~mm} \mathrm{~s}^{-1}$; b) $6 \mathrm{~mm}-1000 \mathrm{~mm} \mathrm{~s}^{-1}$; c) $10 \mathrm{~mm} \mathrm{-} 100$ $\mathrm{mm} \mathrm{s}^{-1}$; d) $10 \mathrm{~mm}-1000 \mathrm{~mm} \mathrm{~s}^{-1}$; e) $14 \mathrm{~mm} \mathrm{-} 100 \mathrm{~mm} \mathrm{~s}^{-1}$; f) $14 \mathrm{~mm}-1000 \mathrm{~mm} \mathrm{~s}^{-1}$; g) 20 $\mathrm{mm}-100 \mathrm{~mm} \mathrm{~s}^{-1}$ and h) $20 \mathrm{~mm}-1000 \mathrm{~mm} \mathrm{~s}^{-1}$.

Figure 4. Variation of the oxidation level of polyethylene surface $(\mathrm{O} / \mathrm{C}$ ratio obtained by XPS analysis) in terms of the treatment rate for different nozzle-sample distances.

Figure 5. Variation of the maximum shear strength of PE-PE adhesion joints in terms of the treatment rate for different nozzle-sample distances.

Figure 6. SEM images of fractured surfaces (shear tests) of PE-PE adhesion joints with different combinations (nozzle-sample distance; treatment rate). a) $6 \mathrm{~mm}-100 \mathrm{~mm} \mathrm{~s}^{-1}$ and b) $20 \mathrm{~mm}-1000 \mathrm{~mm} \mathrm{~s}^{-1}$.

Figure 7. Variation of the maximum T-peel strength of PE-PE adhesion joints in terms of the treatment rate for different nozzle-sample distances.

Figure 8. SEM images of fractured surfaces (T-peel tests) of PE-PE adhesion joints with different combinations (nozzle-sample distance; treatment rate). a) $6 \mathrm{~mm}-100$ $\mathrm{mm} \mathrm{s}^{-1}$ and b) $20 \mathrm{~mm}-1000 \mathrm{~mm} \mathrm{~s}^{-1}$. 